\title{
Comparison of Collum Angle of Maxillary Central Incisor in High Angle and Low Angle Patients
}

Erum Behroz ${ }^{1}$

Hafiz Zuhair Ahmed ${ }^{2}$

S.M. Tariq Rafi ${ }^{3}$

Tabssum Ahsan Qadeer ${ }^{4}$

Mairah Shah ${ }^{5}$

Samar Fatima ${ }^{6}$

\author{
BDS, FCPS, C- Orth, MTFPDP, C-HPE \\ BDS
}

MBBS, DLO, FCPS, FICS, FRCS

BDS, FCPS

BDS

BDS

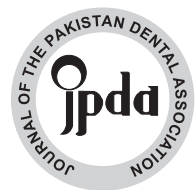

OBJECTIVE: This study aims to determine the mean collum angle of maxillary central incisor and to compare it between high angle and low angle patients undergoing orthodontic treatment.

METHODOLOGY: This cross-sectional, observational study was conducted using lateral cephalometric radiographs of 61 class II division 1 patients (comprised 32 males, 29 females, age range 13 to 30 years) from the record files of patients inducted for Orthodontic management from June 2020 till August 2020 at the Department of Orthodontics, Sindh Institute of Oral Health Science, Jinnah Sindh Medical University, Karachi, Pakistan. The sample was divided on the basis of Vertical Analysis (angulation of mandibular plane) into high and low angle cases. Collum angle was measured using the angulation of the Maxillary Central Incisor (MCI). Student t-test was used to compare the mean difference of the collum angle between skeletal vertical malocclusions. RESULTS: Mean value of the collum angle for high angle (Vertical Growth pattern) cases were mean \pm standard deviation $\left(4.35^{\circ} \pm 1.49^{\circ}\right)$ while for low angle groups (Horizontal Growth pattern) were $\left(2.41^{\circ} \pm 1.60^{\circ}\right)$.

CONCLUSION: There Collum angle of permanent maxillary central incisors differ significantly $(\mathrm{p}<0.001)$ among high angle and Low angle malocclusions cases $(\mathrm{n}=61)$ and showed pronounced axial bending in Class II division 1 incisors with high angle $\left(4.35^{\circ} \pm 1.49^{\circ}\right)$ as compared to low angle malocclusion $\left(2.41^{\circ} \pm 1.60^{\circ}\right)$.

KEYWORDS: Collum Angle, Maxillary Central Incisor, Orthodontic Treatment, High Angle, Low Angle.

HOW TO CITE: Behroz E, Ahmed HZ, Rafi S.M.T, Qadeer TA, Shah M, Fatima S. Comparison of collum angle of maxillary central incisor in high angle and low angle patients. J Pak Dent Assoc 2021;30(2):113-117.

DOI: https://doi.org/10.25301/JPDA.302.113

Received: 16 December 2020, Accepted: 08 March 2021

\section{INTRODUCTION}

0 mile, facial appearance, and social behavior are a few major factors for seeking orthodontic treatment. ${ }^{1,2}$ Upper central incisors are the first teeth to be visible during normal facial activity. Severe malalignment of these teeth results in poor facial esthetics, affecting lip competence, and ideal occlusion. More often a small malalignment of

1. Associate Professor, Department of Orthodontics, Sindh Institute of Oral Health Sciences, Karachi, Sindh, Pakistan.

2. FCPS Part-II Trainee, Department of Orthodontics, Sindh Institute of Oral Health Sciences, Karachi, Sindh, Pakistan.

3. Vice Chancellor, Jinnah Sindh Medical University, Karachi, Sindh, Pakistan.

4. Associate professor, Department of Orthodontics, Bahria University Medical and Dental College, Karachi, Sindh, Pakistan.

5. FCPS Part -II Trainee, Department of Orthodontics, Sindh Institute of Oral Health Sciences, Karachi, Sindh, Pakistan.

6. FCPS part-II Trainee, Department of Orthodontics, Sindh Institute of Oral Health Sciences, Karachi, Sindh, Pakistan.

Corresponding author: "Dr. Erum Behroz Khan" < erum.behroz@jsmu.edu.pk > these teeth is the major concern for the patients. ${ }^{3}$

Each tooth has a specific morphology based on crown width, height, angulation, and, structural formation, which has a strong genetic control. ${ }^{4}$ Crown to root angulation also called collum angle CA (measured between the long axis of the crown and the root) is significant from the perspective of orthodontic treatment and whenever implants are required ${ }^{5,6}$ and this is most significant for the maxillary central incisors. Ideal occlusion of anterior teeth is necessary to overcome esthetic problems and is dependent on the labial and lingual inclination of the incisors. Crown root angulation also determines the degree of maxillary central incisor to be torqued to prevent the perforation of buccal and lingual cortical plates. ${ }^{3}$ Variation in root angulation of the incisors has been made evident in various studies ${ }^{7}$, as it might leads to undesirable force application during movements like intrusion and extrusion. ${ }^{7}$ 
As the Collum angle increases intrusion of the tooth in the alveolar bone decreases as the center of rotation moves downward towards the tooth cervix and strain in the periodontal ligament increases. ${ }^{12,21}$

Some studies indicated a change in the CA between different malocclusion as well as among high and low angle cases, however such a study has not been conducted on our population. Previously this angle was studied using CBCT and $\mathrm{CT}^{3,6-11}$, however cephalometric radiography has also been widely utilized for this purpose and generated better results. ${ }^{7,25,4,10}$

The aim of this study was to compare the collum angle of upper central incisors between vertical malocclusions using lateral cephalogram, in a sample population. Collum angle has been previously studied in different types of sagittal malocclusion but no such study has focused on vertical malocclusion in our population. Since collum angle is responsible for variation in torque expression, root resorption, fenestration and dehiscence, with prior knowledge of collum angle in high angle and low angle cases, operator can prevent above deleterious effects and accompanied better bracket positioning in future orthodontic treatment.

\section{METHODOLOGY}

The study was a cross-sectional observational study, conducted at the Department of Orthodontics, Sindh Institute of Oral Health Science, Jinnah Sindh Medical University, Karachi, Pakistan. The study included lateral cephalometric radiographs of 61 patients having class II malocclusion with class II div 1 incisor relationship and was conducted from June 2020 to August 2020. Sample size was calculated by using WHO sample size calculator

$$
\left(\mathrm{n}=\frac{z 2 \frac{1-\alpha}{2} \sigma 2}{d 2} \text { or } \frac{z 2 \frac{1-\alpha}{2} \sigma 2}{\varepsilon 2 \mu 2}\right) \text {. }
$$

A study by Isaar et al reported the collum angle of maxillary central incisor in class II div 1 as $3.65 \pm 3.79$ degree in our population. Keeping this value as a reference, confidence of interval $95 \%$ and margin of error $1 \%$ sample requirement turned out to be 56, however, 61 sample size was taken. Consecutive sampling was used to gather the data from patients of both genders with ages ranging from 13 to 30 years who came to seek orthodontic treatment. The researcher categorized the patients into two groups of vertical skeletal malocclusion as a high angle and a low angle on the bases SNMP angle taken on lateral cephalogram. Consecutive sampling technique was used. The sample included patients of both genders, with ages ranging from 13 to 30 years, who came to the department seeking Orthodontic treatment. Patients with supernumerary teeth, hypodontia, fixed or removable prostheses, orofacial clefts or other craniofacial syndromes, poor incisor definition due to superimposed teeth, incisor rotations, any surgical treatment history, or inferior image quality of lateral cephalogram, were excluded from our study.

A single calibrated examiner traced all the cephalometric radiographs, located all points, and measured all angles. The sample was divided into high and low angle based on the value of SNMP, FHMP and MMA (SN-MP > 37 , FH-MP $>30^{\circ}$, MMA $>28^{\circ}$ for high angle, SN-MP $<28^{\circ}$, FH-MP $<21^{\circ}$, MMA $<21^{\circ}$ for low angle).

Collum angle was drawn and measured on a proforma for each patient.

Collum Angle Measurement: Collum angle was measured and reported in terms of degrees. This angle is formed by the longitudinal axis of the crown and the root. The longitudinal axis of the incisor is a line passing through the midpoint of the cutting edge of the incisor to the radiographic center point of the crown at CEJ. The longitudinal axis of the root is a line passing through the radiographic apex to the midpoint between the lingual and facial projection of the cementoenamel junction. ${ }^{7}$ Shown in Figure $1 .{ }^{7}$

Figure-1: Schematic representation of measurement of the Collum Angle

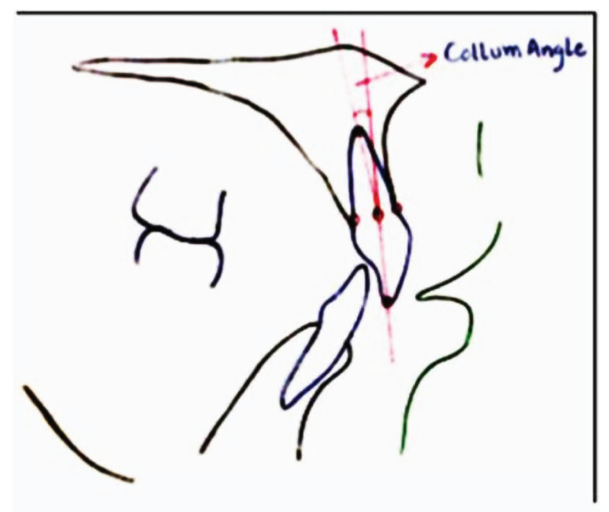

Table 1: Grouping of the Patients

\begin{tabular}{|l|c|c|}
\hline Skeletal vertical malocclusion & \multicolumn{1}{c|}{ Criteria for groups } & No. of patients \\
\hline High angle patient & SN-MP $>37^{\circ}$, FH-MP $>29^{\circ}$, MMA $>29^{\circ}$ & 34 \\
Low angle patient & SN-MP $<28^{\circ}$, FH-MP $<21^{\circ},{\text { MMA }<21^{\circ}}^{\circ}$ & 27 \\
\hline
\end{tabular}

\section{STATISTICAL ANALYSIS}

This study used SPSS 25 for Windows (SPSS, Inc.; Chicago, Illinois) for data entry and analysis. The mean and the standard deviation were calculated of the quantitative variable such as age and collum angle. Frequency and percentages were presented for the qualitative data such as 
Behroz E/ Ahmed HZ/ Rafi S.M.T/

Qadeer TA/ Shah M/ Fatima S/

gender and profiles of the patient i.e. high/low. In this study the significance level was set as 5\%, using the stratification technique the confounding factor such as age group and gender were modified and controlled. Student t-test was used to compare the mean difference of collum angle between profiles of the patient i.e. high/low.

\section{RESULTS}

The descriptive statistics has been shown in Table 2 . The Pearson chi-square test is used for finding an association of the gender with the profile of the patients which is presented in Table-3. We found an insignificant association between gender and profile of the patients i.e. $(p=0.269)$. The mean age of the patients was $18.44 \pm 4.56$ years in high angle and $19.37 \pm 4.20$ years in low angle. We found an insignificant difference in the profile of the patients with respect to age i.e. $(p=0.417)$. To compare the collum angle with the patient's profile, an independent-sample t-test was used. The mean collum angle of the patients was $4.35 \pm 1.49^{\circ}$ in high angle

Table 2: Descriptive Statistics

\begin{tabular}{|l|l|}
\hline Age $($ Mean \pm SD) & $18.85 \pm 4.40$ \\
\hline Collum angle (Mean \pm SD) & $3.49 \pm 1.81$ \\
\hline Gender & \\
\hline Male & $32(52 \%)$ \\
\hline Female & $29(47 \%)$ \\
\hline Profile of the patients & \\
\hline High Angle & $34(55.7 \%)$ \\
\hline Low Angle & $27(44.3 \%)$ \\
\hline
\end{tabular}

Table 3: Association of gender with the profile of the patients

\begin{tabular}{|l|l|l|l|}
\hline \multirow{2}{*}{ Gender } & \multicolumn{2}{|l|}{ Profile of the patients } & \multirow{2}{*}{ P-value } \\
\cline { 2 - 3 } & High Angle & Low Angle & \\
\hline Male & $16(26.6 \%)$ & $16(26.6 \%)$ & \multirow{2}{*}{0.269} \\
\hline Female & $18(29.5 \%)$ & $11(18.0 \%)$ & \\
\hline
\end{tabular}

Pearson Chi-square test is applied $\mathrm{p}<0.05$

and $2.41 \pm 1.60^{\circ}$ in low angle. We found a highly significant difference in the profile of the patients with respect to the collum angle i.e. $(\mathrm{p}=0.000)$. The detailed mean difference of age and collum angle with respect to the profile of the patients is presented in Table-4. The detailed mean difference of age and collum angle with respect to the profile of the patients is presented in Table-5.
Comparison of collum angle of maxillary central incisor in high angle and low angle patients

Table 4: Mean difference of age and collum angle w.r.t profile of the patients

\begin{tabular}{|l|l|l|l|}
\hline \multirow{2}{*}{ Characteristics } & \multicolumn{2}{|l|}{ Profile of the patients } & \multirow{2}{*}{ P-value } \\
\cline { 2 - 4 } & High Angle & Low Angle & \\
\hline Age & & & \\
\hline Collum Angle & $18.44 \pm 4.56$ & $19.37 \pm 4.20$ & 0.417 \\
\hline
\end{tabular}

Student t-test is applied $\mathrm{p}<0.05$

Table 5: Mean difference of age and collum angle w.r.t gender

\begin{tabular}{|l|l|l|l|}
\hline \multirow{2}{*}{ Characteristics } & \multicolumn{2}{|l|}{ Gender } & \multirow{2}{*}{ P-value } \\
\cline { 2 - 3 } & Male & Female & \\
\hline Age & $19.07 \pm 4.53$ & $18.79 \pm 4.40$ & 0.838 \\
\hline Collum Angle & & & \\
\hline
\end{tabular}

\section{DISCUSSION}

The anterior torque expressed in the bracket is essential to attain the normal overjet, overbite, satisfactory esthetic, and ideal dental relationship. For ideal tooth positioning in pre-adjusted straight wire appliance, two factors are important, first ideal bracket positioning on the labial and buccal surfaces of the tooth to obtain ideal tip and torque of individual tooth, second normal crown root morphology but the ideal torque is difficult to express because of variation in morphology in each tooth, different wire material properties, different slots sizes, ligation methods, and clinician experience. ${ }^{12}$

Andrews' pre-adjusted straight wire concept had six keys of ideal occlusion ${ }^{13,14}$ the third key was the correct inclination of the crown and the Collum angle was assumed to be zero for each tooth. ${ }^{13}$ This assumption of Andrews has been applied in lateral cephalometric tracing and frequently used since then. The difference in crown forms and position of roots to the natural crown has provided some evident limitations to the straight wire appliance which can be frequently observed and overcome by the bracket positioning and wire bending subjected to the clinician's experience. Many authors have explained about collum angle formation, bending of the maxillary central incisor is the main cause. Backlund $^{22}$ et al stated that the lower lip generates the force that affects maxillary central incisor growth leading to bending of the tooth thus collum angle is formed. Other authors have investigated that genetics and hereditary influence is also one of the reasons behind maxillary incisor bending phenomena. ${ }^{4,23}$

Anterior teeth movement is restricted by the thickness of the alveolar bone and the vertical alveolar height of the regional alveolar bone and not affected by the root length ${ }^{15}$ 
while little importance was given to the morphological limitations of the tooth. Some authors suggest that differences in the morphology should be given more importance because of the difference among various types of pre-adjusted brackets systems. ${ }^{16}$

Maxillary central incisor resorption is influenced by changes in the treatment and mechanics. Kaley and Phillips ${ }^{25}$ in 1991 reported that root translation or torqueing into the palatal cortex significantly increases the chances of root resorption. For example, in case of extruded and protruded teeth, especially maxillary central incisor will be intruded first, in order to bring the root apex in the wider cancellous bone area followed by retraction and torqueing mechanics that is why, in order to achieve better predictability in root position, and to overcome the difficulties with intrusion, extrusion, or torqueing mechanics, a good understanding of crown-root relationships in the bucco-lingual plane is needed. ${ }^{20}$

Bryant was the first one to study the effect of variability in incisor morphology on torque expression and he postulated three morphological landmarks of the upper central incisor, ${ }^{5}$ the landmarks that were obtained from the proximal aspects were lingual crown curvature, labial surface angle (a tangent drawn from the labial surface of the tooth on the bracket bonding site to the long axis of the tooth), and the supplementary angle of collum angle or crown to root angulation (between the longitudinal axis of the crown and the root). The second and third morphological feature of anterior teeth has been focused in the following studies. ${ }^{7,9,16}$ Before CBCT (Cone beam computed tomography) was invented lateral cephalometry was the only way to investigate labial surface angle and collum. ${ }^{4,17,18} \mathrm{CA}$ of maxillary central incisor in sagittal malocclusion has been studied previously in western population ${ }^{19,10,20,3,6}$ as well in Pakistani population ${ }^{7,24}$ but vertical skeletal malocclusion using lateral cephalogram has not been studied, which was the reason we chose to explore this aspect.

Williams ${ }^{19}$ et al measured the crown root angles of maxillary central incisor in all four classes of malocclusion and reported significant difference among class II div 1 and div 2 malocclusion.

Srinivasan ${ }^{10}$ et al measured the CA of MCI in class II div 2 patients and reported $5.3^{\circ} \pm 4.2^{\circ}$ average value in class II div 1 and $10.6^{\circ} \pm 4.4^{\circ}$ for Class II division 2 samples and stated that the difference in magnitude is affected by the lower lip line.

Bauer $^{20}$ et al measured the CA of maxillary central incisor in class I, class II division 2 malocclusion, compare the $\mathrm{CA}$ and reported the significantly increased CA in class II div 2 samples . $\left(1.78^{\circ} \mathrm{VS} 4.29^{\circ}\right)$

Israr $^{7}$ et al reported the CA of upper central incisor in class II div 1 and div 2 as $3.65+-3.79$ and $10.03+-4.37$ degree with the greater CA in class II div 2 pattern. According to Zahra ${ }^{24}$ et al.CA of upper central incisor for class I, class II div 1, class II div 2, and class III were reported as $5.12 \pm 3.78,6.09 \pm 4.57,15.02 \pm 7.99$, and $6.94 \pm 3.80$, respectively, with increased CA in class II div 2 pattern. We found Collum angle not statistically different for males as compared to females. The current study measured the mean collum angle of maxillary central incisors in skeletal vertical malocclusions and reported $4.35 \pm 1.49^{\circ}$ for high angle and $2.41 \pm 1.60^{\circ}$ for low angle. This study also showed that there is strong significant difference in collum angle of high angle compared to low angle cases with increase collum angle in high angle cases and decrease in low angle cases suggesting that morphology of maxillary central incisor play an important role in root resorption, dehiscence, fenestration and torque variation because of the root bending phenomenon. For operators point of view crown root morphology need to be assessed before bracket positioning.

Wang $^{3}$ et al measured the collum angle(CA) of the maxillary central incisor(MCI) in different vertical malocclusions and reported the value to be $0.94^{\circ} \pm 6.71^{\circ}$ in high, $-1.02^{\circ} \pm 6.30^{\circ}$ in average, and $1.74^{\circ} \pm 5.28^{\circ}$ in low angle cases. However his results showed that the differences were not statistically significant. Our study on the other hand showed significant variations in CA between different vertical values.

Harris concluded that there was no correlation between CA and lower face height, FH-MP(Frankfurt horizontal plane to mandibular plane),PP-FH(Palatal plane to Frankfurt horizontal plane), and OP-FH(Occlusal plane to Frankfurt horizontal plane) for vertical growth pattern ${ }^{4}$, our results were however different showing a correlation indicating ethnic and racial predisposition to CA.

Our study had some limitations including a small sample size, also for our future studies we would like to compare this value between the younger and older age group, to see if the angle changes due to constant strain from the lip as the age progresses. Socio economic status of the patients affecting the strain might also have an interesting effect on the results of such a study.

\section{CONCLUSION}

Our study concluded that there is a highly significant difference in mean collum angle between high angle and low angle malocclusions.

\section{ETHICAL APPROVAL}

Attached. 
Behroz E/ Ahmed HZ/ Rafi S.M.T/

Qadeer TA/ Shah M/ Fatima S/

\section{COMPETING INTERESTS}

Authors have declared that no competing interests exist.

\section{REFERENCES}

1. Kilpelanien P, Phillips C, Tulloch JFC. Anterior tooth position and motivation for early treatment. Angle Orthod 1993; 63: 171-74.

2. Mehu M, Dunbar RIM. Naturalistic observations of smiling and laughter in human group interactions. Behaviour. 2008;145:1747-80. https://doi.org/10.1163/156853908786279619

3. Wang X ming, Ma L zhi, Wang J, Xue H. The crown-root morphology of central incisors in different skeletal malocclusions assessed with cone-beam computed tomography. Prog Orthod. 2019;20:1-11. https://doi.org/10.1186/s40510-019-0272-2

4. Harris EF, Hassankiadeh S, Harris JT. Maxillary incisor crown-root relationships in different Angle malocclusions. Am J Orthod Dentofac Orthop. 1993;103:48-53.

https://doi.org/10.1016/0889-5406(93)70104-V

5. Bryant RM, Sadowsky PL, Dent M, Hazelrig JB. Variability in three morphologic features of the permanent maxillary central incisor. Am J Orthod. 1984;86:25-32.

https://doi.org/10.1016/0002-9416(84)90273-2

6. Shen YW, Hsu JT, Wang YH, Huang HL, Fuh LJ. The Collum angle of the maxillary central incisors in patients with different types of malocclusion. J Dent Sci [Internet]. 2012;7:72-6.

https://doi.org/10.1016/j.jds.2012.01.010

7. Israr J, N B, Chatha M. Comparison of Collum Angle of Maxillary Central Incisors in Class II div 1 \& 2 Malocclusions. Pak Oral Dent J. 2016;36:91-4.

8. Delivanis HP, Kuftinec MM. Variation in morphology of the maxillary central incisors found in Class II, Division 2 malocclusions. Am J Orthod. 1980;78:438-43.

https://doi.org/10.1016/0002-9416(80)90024-X

9. Kong WD, Ke JY, Hu XQ, Zhang W, Li SS, Feng Y. Applications of cone-beam computed tomography to assess the effects of labial crown morphologies and collum angles on torque for maxillary anterior teeth. Am J Orthod Dentofac Orthop. 2016;150:789-95.

https://doi.org/10.1016/j.ajodo.2016.03.029

10. Srinivasan B, Kailasam V, Chitharanjan A, Ramalingam A. Relationship between crown-root angulation (collum angle) of maxillary central incisors in Class II, division 2 malocclusion and lower lip line. Orthodontics (Chic). 2013;14:e66-74.

https://doi.org/10.11607/ortho.841

11. Feres M, Rozolen B, Alhadlaq A, Alkhadra T, El-Bialy T. Comparative tomographic study of the maxillary central incisor collum angle between Class I, Class II, division 1 and 2 patients. J Orthod Sci. 2018;7:6. https://doi.org/10.4103/jos.JOS_84_17
Comparison of collum angle of maxillary central incisor in high angle and low angle patients

12. Papageorgiou SN, Sifakakis I, Keilig L, Patcas R, Affolter S, Eliades $\mathrm{T}$, et al. Torque differences according to tooth morphology and bracket placement: a finite element study. Eur J Orthod. 2017;39:411-8. https://doi.org/10.1093/ejo/cjw074

13. Andrews L. The concept and appliance. In: the concept and appliance. 1989.

14. Andrews LF. The six keys to normal occlusion. Am J Orthod. 1972; https://doi.org/10.1016/S0002-9416(72)90268-0

15. Sun B, Tang J, Xiao P, Ding Y. Presurgical orthodontic decompensation alters alveolar bone condition around mandibular incisors in adults with skeletal Class III malocclusion. Int J Clin Exp Med. 2015;8:12866

16. Knösel M, Jung K, Attin T, Engelke W, Kubein-Meesenburg D, Gripp-Rudolph L, et al. On the interaction between incisor crown-root morphology and third-order angulation. Angle Orthod. 2009;79:45461.

https://doi.org/10.2319/042508-234

17. Wood WD. Orthodontic therapy. J Am Dent Assoc. 2002;133. https://doi.org/10.14219/jada.archive.2002.0309

18. Kanj AH, Bouserhal J, Osman E, El Sayed AAM. The inflection point: a torque reference for lingual bracket positioning on the palatal surface curvature of the maxillary central incisor. Prog Orthod. 2018;19:1-11 https://doi.org/10.1186/s40510-018-0234-0

19. Williams A, Woodhouse $\mathrm{C}$. The crown to root angle of maxillary central incisors in different incisal classes. Br J Orthod. 1983;10: 159-61.

https://doi.org/10.1179/bjo.10.3.159

20. Bauer, Thomas J. Maxillary central incisor crown-root relationships in Class I normal occlusions and Class II division 2 malocclusions (MS thesis). University of Iowa; 2014.

21. Pai SS, Panda S, Pai V, Anandu M, Vishwanath E, Suhas AS. Effects of labial and lingual retraction and intrusion force on maxillary central incisor with varying collum angles: A three-dimensional finite elemental analysis. J Indian Orthod Soc. 2017;51:28-37.

https://doi.org/10.4103/0301-5742.199252

22. Backlund E. Tooth form and overbite. Trans Eur Orthod Soc 1960; 36: 97-103.

23. Logan WR. Deckbiss-a clinical evaluation. Trans Eur Orthod Soc 1959; 35: 313-17.

24. Khalid Z, Iqbal K, Khalid S, Riaz A, Jan A. Comparison of collum angle of maxillary central incisors in different incisor relationships. J Coll Physicians Surg Pak. 2020;30:471-75. https://doi.org/10.29271/jcpsp.2020.05.471

25. Kaley J, Phillips C. Factors related to root resorption in edgewise practice. Vol. 61, Angle Orthodontist. 1991. p. 125-32. 